\title{
Effectiveness of education intervention carried out by clinical pharmacist on quality of life of patients with COPD: A randomized controlled trial
}

\author{
Quynh Thi Huong Bui1*, \\ Anh Thi Duyen Nguyen ${ }^{1}$ \\ 1Department of Clinical Pharmacy, \\ Faculty of Pharmacy, University of \\ Medicine and Pharmacy at Ho Chi Minh \\ City, Vietnam
}

*Corresponding author:

Quynh Thi Huong Bui bthquynh@ump.edu.vn

\begin{abstract}
Chronic obstructive pulmonary disease (COPD) is a disease affecting the patient's ability to perform normal daily physical and social activities, thereby affecting their quality of life (QoL). The aim of this study was to evaluate the effectiveness of education intervention carried out by clinical pharmacists on COPD patients' QoL. A randomized, controlled trial was conducted at Department of Screening Respiratory Function, University Medical Center, Ho Chi Minh City, Vietnam from December 2017 to May 2018. Patients aged 40 years or older, who were diagnosed with COPD and agreed to participate were included in this study. Selected patients were randomized into two groups, the intervention group (IG) and the non-intervention group (NIG). The clinical pharmacist intervention program included education about COPD knowledge, medication usage, inhaler technique, the importance of medication adherence and smoking cessation, lifestyle adjustments, recognition and prevention of possible adverse drug effects. Participants were followed up by monthly telephone calls. Patients' QoL was measured by the validated Vietnamese version of the Clinical COPD Questionnaire (CCQ). The main outcome was the difference in QoL scores between IG and NIG after the three-month followup. After three months, the number of patients in the IG and in the NIG was 73 and 68, respectively. The total CCQ score improved significantly after the pharmacist intervention $(0.81 \pm 0.54$ in the IG vs. $1.24 \pm 0.81$ in the NIG, $p<0.001)$. Our study suggests that clinical pharmacist-led education can improve COPD patients' QoL.
\end{abstract}

\section{INTRODUCTION}

Chronic obstructive pulmonary disease (COPD) is a common disease of the respiratory system, which is one of the major causes of morbidity and mortality worldwide ${ }^{1}$. COPD continues to increase in both developed and developing countries ${ }^{2}$. Vietnam is predicted to have the highest COPD prevalence (6.7\%) in the Asia-Pacific region ${ }^{3}$. Patients with COPD commonly suffer critical health problems such as reduced quality of life (QoL) and increased economic burden.

COPD has been described as " $10 \%$ medication and $90 \%$ education"4. Management of COPD is complex, included behavioral and lifestyle changes such as smoking cessation, proper use of inhalation technique, adherence to exercise therapy and optimal, https://www.pharmacy.mahidol.ac.th/journal/ (C) Faculty of Pharmacy, Mahidol University (Thailand) 2020 
medication adherence ${ }^{5}$. Pharmacists can help patients to understand their condition, the importance of prescribed medications and lifestyle changes to improve their QoL and clinical outcomes ${ }^{6}$.

Some previous studies have demonstrated that pharmacist-led educational interventions may improve the health outcomes of patients with COPD $^{6}$. However, in Vietnam, treatment for COPD is mainly provided by doctors or nurses, while pharmacist-led education remains largely under-used across the healthcare system. One reason is the critical shortage of the quantity and quality of pharmacists in Vietnam ${ }^{7}$, particularly clinical pharmacists. Therefore, this study aimed to evaluate the effectiveness of education interventions implemented by pharmacists involving face-to-face and telephone counseling on COPD patients' QoL.

\section{MATERIALS AND METHODS}

\subsection{Study settings}

This was a parallel - group, randomized, controlled trial with a 3 month follow - up.

\subsection{Participants}

According to the following inclusion and exclusion criteria:

\subsubsection{Inclusion criteria}

- Patients diagnosed with COPD, who visited the Department of Screening Respiratory Function, University Medical Center, from December 15, 2017 to May 15, 2018.

- Aged 40 years or older. the study.

- Patients who accepted to participate in

\subsubsection{Exclusion criteria}

- Patients with insufficient personal information or did not provide a contact address.

- Patients who had an impaired cognitive situation or dementia.

- Patients who did not have or could not use a mobile phone/telephone.

\subsection{Sample size}

The required sample size for each group was calculated using the following formula:

$$
\begin{gathered}
n=\frac{2 C}{\mathrm{ES}^{2}}=\frac{2 C}{\left(\frac{\Delta}{\sigma}\right) 2} \\
C=7.85(\alpha=0.05, \text { reliability } 95 \%, \beta=
\end{gathered}
$$
0.2 and power $=0.8) . \sigma$ is the standard deviation of the mean QoL score by the Clinical COPD Questionnaire. $\Delta$ is the difference in QoL score between the intervention group (IG) and the nonintervention group (NIG). According to the study of Le Khac Bao, $\sigma$ was $1.0^{8}$. The desired $\Delta$ was 0.5 . Therefore, the minimum sample size for each group was 63. In this study, we selected 92 patients in the IG and 93 patients in the NIG.

\subsection{Study process}

Sampling took place in the Department of Screening Respiratory Function, University Medical Center, while the follow-up was conducted via monthly phone calls. Selected patients were randomized into two groups, IG and NIG, using a list composed by the website www.random.org. Three pharmacists took part in the sampling, interviewing, and follow-up process. Before we started the study, the three pharmacists were trained on the consultation process by the principal investigator, then they passed the oral test checked by the scientific committee, including the head of clinical pharmacy department and a simulated patient to ensure the consistency between the three pharmacists.

The NIG patients only received usual hospital outpatient care by the doctors and nurses. In addition to usual care, the IG patients were educated by the clinical pharmacist about COPD knowledge, medication usage, inhaler technique, the importance of medication adherence and smoking cessation, lifestyle adjustments, recognition and prevention of possible adverse drug effects (ADEs). This information was provided based on the Global Initiative for Chronic Obstructive Lung Disease 2017 (GOLD 2017) ${ }^{9}$ and the Guidelines for diagnosis and treatment of chronic obstructive pulmonary disease of the Ministry of Health Vietnam $(2015)^{10}$.

The counselling sessions were carried out in IG patients at the hospital and lasted about 20 - 30 minutes. Patient education materials about medications and lifestyle changes, especially on how to use the inhaler device were prepared and distributed to patients for reinforcing the content delivered through counselling, patients were allowed to take a copy 
to their home. These patients would receive follow-up telephone calls by the clinical pharmacist at the $1^{\text {st }}, 2^{\text {nd }}, 3^{\text {rd }}$ month after the first meeting. During 20 minutes of each telephone counselling, the pharmacist asked the IG patients about the treatment effects, explained the possible ADEs, reinforced the education, recommended the patients about adjusting their lifestyles and reminded when the patients should visit their doctor.

At the beginning of the study, baseline data for all participating patients were collected by pharmacist included demographic measures, disease characteristics, respiratory medications. QoL scores based on the validated Vietnamese version of the Clinical COPD Questionnaire $(\mathrm{CCQ})^{11}$ were also calculated for all patients, at the beginning of the study at the hospital, and $1^{\text {st }}, 2^{\text {nd }}$, $3^{\text {rd }}$ month after they joined the study by telephone. Higher CCQ score denotes a lower quality of life.

\subsection{Statistical analysis}

The data were analyzed using Statistical Package for Social Sciences (SPSS) Program, version 20.0. Patient's data were presented as mean \pm S.D., median (interquartile range $25-75 \%$ ) or percentage. The comparison of percentages between the IG and the NIG were assessed using the Chi-square test. The T-test or Mann Whitney test was used to test for significant differences in QoL scores and the mean change $(\Delta)$ in QoL score three months after the intervention. The possible associated factors (intervention, age, body mass index, smoking status, pack - year, education level, living area, GOLD classification, COPD duration, combination route (yes/no), number of comorbidities, error in inhaler technique (defined as "Yes" if a participant had at least one incorrect step of inhaler usage and "No" if all steps were correct) on the change in $\mathrm{QoL}$

Table 1. Baseline characteristics of patients in the two study groups

\begin{tabular}{|c|c|c|c|c|}
\hline \multirow{2}{*}{\multicolumn{2}{|c|}{ Characteristics }} & \multicolumn{2}{|c|}{ Group } & \multirow{2}{*}{$p$ value } \\
\hline & & IG $(\mathbf{n}=92)$ & NIG $(n=93)$ & \\
\hline \multicolumn{2}{|l|}{ Gender (Male) } & $91(98.9 \%)$ & $90(96.8 \%)$ & 0.317 \\
\hline \multicolumn{2}{|l|}{ Mean Age } & $63.80 \pm 9.96$ & $66.08 \pm 8.67$ & 0.100 \\
\hline \multirow{2}{*}{\multicolumn{2}{|c|}{$\begin{array}{l}40-60 \\
>60\end{array}$}} & $31(33.7 \%)$ & $20(21.5 \%)$ & \\
\hline & & $61(66.3 \%)$ & $73(78.5 \%)$ & 0.064 \\
\hline \multicolumn{2}{|l|}{$\mathrm{BMI}\left(\mathrm{kg} / \mathrm{m}^{2}\right)$} & $21.49 \pm 3.24$ & $21.83 \pm 3.55$ & 0.491 \\
\hline \multirow{6}{*}{ Education level } & Illiterate & $1(1.1 \%)$ & $1(1.1 \%)$ & \multirow{6}{*}{0.641} \\
\hline & Primary & $25(27.2 \%)$ & $31(33.3 \%)$ & \\
\hline & Secondary & $31(33.7 \%)$ & $22(23.7 \%)$ & \\
\hline & High school & $26(28.3 \%)$ & $27(29.0 \%)$ & \\
\hline & University/college & $9(9.8 \%)$ & $11(11.8 \%)$ & \\
\hline & Postgrad & $0(0 \%)$ & $1(1.1 \%)$ & \\
\hline \multirow{2}{*}{ Living area } & Rural & $58(63.0 \%)$ & $54(58.1 \%)$ & \multirow{2}{*}{0.488} \\
\hline & Urban & $34(37.0 \%)$ & $39(41.9 \%)$ & \\
\hline \multirow{3}{*}{ Smoking status } & Non - smoker & $3(3.3 \%)$ & $4(4.3 \%)$ & \multirow{3}{*}{0.921} \\
\hline & Former smoker & $63(68.5 \%)$ & $64(68.8 \%)$ & \\
\hline & Current smoker & $26(28.3 \%)$ & $25(26.9 \%)$ & \\
\hline \multicolumn{2}{|l|}{ Pack - year } & $34.91 \pm 18.59$ & $36.73 \pm 18.90$ & \multirow[t]{2}{*}{0.535} \\
\hline \multirow{4}{*}{$\begin{array}{l}\text { GOLD } \\
\text { classification }\end{array}$} & A & $5(5.4 \%)$ & $5(5.4 \%)$ & \\
\hline & B & $27(29.3 \%)$ & $29(31.2 \%)$ & \multirow{3}{*}{0.409} \\
\hline & $\mathrm{C}$ & $18(19.6 \%)$ & $10(10.8 \%)$ & \\
\hline & $\mathrm{D}$ & $42(45.7 \%)$ & $49(52.7 \%)$ & \\
\hline COPD duration & & $3.88 \pm 3.80$ & $4.63 \pm 4.52$ & 0.421 \\
\hline \multirow{4}{*}{ Comorbidities } & Yes & $78(84.8 \%)$ & $69(74.2 \%)$ & 0.075 \\
\hline & Hypertension & $43(46.7 \%)$ & $42(45.2 \%)$ & 0.830 \\
\hline & Gastritis & $15(16.3 \%)$ & $14(15.1 \%)$ & 0.815 \\
\hline & Ischemic heart disease & $10(10.9 \%)$ & $12(12.9 \%)$ & 0.669 \\
\hline \multicolumn{2}{|l|}{ Total CCQ score } & $1.73 \pm 0.95$ & $1.57 \pm 1.05$ & 0.140 \\
\hline \multicolumn{2}{|c|}{ Symptom score } & $2.16 \pm 1.11$ & $1.90 \pm 1.08$ & 0.128 \\
\hline \multicolumn{2}{|c|}{ Functional state score } & $1.54 \pm 1.10$ & $1.53 \pm 1.32$ & 0.552 \\
\hline \multicolumn{2}{|c|}{ Mental state score } & $1.23 \pm 1.56$ & $0.98 \pm 1.60$ & 0.109 \\
\hline
\end{tabular}

Mean age, BMI, pack - year, COPD duration, total CCQ score, symptom score, functional state score, mental state score were compared using t-test or Mann-Whitney test. Rates of gender, age group, education level, smoking status, GOLD classification, comorbidities were Chi - square test.

Abbreviation. BMI, Body Mass Index; GOLD, Global Initiative for Chronic Obstructive Lung Disease; 
Table 2. Baseline medication usage in the two study groups

\begin{tabular}{llccc}
\hline & & \multicolumn{2}{c}{ Group } & \multirow{2}{*}{ p value } \\
\cline { 3 - 4 } & & IG (n=92) & NIG (n=93) & \\
\hline Administration & Combination route & $66(71.7 \%)$ & $72(77.4 \%)$ & 0.375 \\
& Inhalation & $26(28.3 \%)$ & $21(22.6 \%)$ & 0.705 \\
\hline Percentage of & SABA & $13(14.1 \%)$ & $15(16.1 \%)$ & 0.770 \\
prescribed inhalation & LABA & $23(25.0 \%)$ & $25(26.9 \%)$ & 0.708 \\
drug & LAMA & $41(44.6 \%)$ & $44(47.3 \%)$ & 0.835 \\
& SABA/SAMA & $57(62 \%)$ & $59(63.4 \%)$ & 0.641 \\
& LABA/LAMA & $3(3.3 \%)$ & $2(2.2 \%)$ & 0.668 \\
& ICS/LABA & $27(29.3 \%)$ & $30(32.3 \%)$ & 0.505 \\
\hline Percentage of & SMART & $36(39.1 \%)$ & $31(34.4 \%)$ & 0.989 \\
prescribed oral drug & LABA & $3(3.3 \%)$ & $3(3.2 \%)$ & 0.527 \\
& OCS & $4(4.3 \%)$ & $6(6.5 \%)$ & 0.418 \\
& Theophylline & $43(46.7 \%)$ & $49(52.7 \%)$ & 0.449 \\
& Mucolytic agents & $25(27.2 \%)$ & $30(32.3 \%)$ & 0.212 \\
& Antibiotic & $6(6.5 \%)$ & $11(11.8 \%)$ & 0.781 \\
& LTRA & $9(9.8 \%)$ & $8(8.6 \%)$ & 0.070 \\
\hline Inappropriate inhaler technique & $9(9.8 \%)$ & $3(3.2 \%)$ & 0.771 \\
\hline
\end{tabular}

Rates of administration route, percentage of prescribed inhalation drug, percentage of prescribed oral drug were compared using Chi - square test (or Fisher exact test).

Abbreviation. SABA, Short-Acting Beta-Agonists; LABA, Long-Acting Beta-Agonists; LAMA, Long Acting Muscarinic Antagonist; SAMA, Short Acting Muscarinic Antagonist; ICS, Inhaled corticosteroids; SMART, Single Maintenance and Reliever Therapy; OCS, Oral corticosteroids; LTRA, Leukotriene Receptor Antagonists; PPI, Proton Pump Inhibitors.

scores was evaluated by multivariate linear regression analysis. Results were presented as Per Protocol (PP) analysis for the remaining sample after 3-month follow-up. We also considered an Intention-to-treat (ITT) analysis with baseline characteristics of all participants at randomization. In case a patient was lost to follow up, we assumed that the QoL at the 3-month interval was unchanged. A $p$-value of $<0.05$ was considered statistically significant.

\section{RESULTS}

A total of 185 patients were enrolled for our study, included 92 patients in the IG and 93 patients in the NIG. Of these, 141 patients completed follow-up (73 in IG and 68 in NIG).

\section{Baseline characteristics of two study groups}

There was no statistically significant difference between the two groups at baseline, included demographic measures and disease characteristics ( $p>0.05)$. The majority were males $(98.9 \%$ in IG vs. $96.8 \%$ in NIG) with low educational level (under university) and lived in rural areas. Most patients were elderly, the mean age was $63.80 \pm 9.96$ in IG and $66.08 \pm 8.67$ in NIG. The majority of the study participants were current or former smokers, the pack - years was estimated to be $34.91 \pm 18.59$ in IG and $36.73 \pm$ 18.90 in NIG. IG and NIG were also matched for duration of COPD $(3.88 \pm 3.80$ vs. $4.63 \pm 4.52)$, mean $\% \mathrm{FEV}_{1}(53.18 \pm 20.82$ vs. $54.62 \pm 17.57)$. Most patients belonged to GOLD B or D class ( $75 \%$ in IG vs. $83.9 \%$ in NIG), and more than half of the participants reported different comorbidities which included hypertension, gastritis, ischemic heart disease, and other conditions (Table 1).

\section{Medication Characteristics in the Study}

The treatment medications were similar between the two groups. In this study, the combination route (e.g., the inhalation and oral route) was common $(71.7 \%$ in IG vs. $77.4 \%$ in NIG). All patients in this study were prescribed inhaled medication, in which, ICS/LABA combination was the most frequently prescribed medicine $(68.4 \%$ in IG vs. $66.6 \%$ in NIG), followed by SABA/SAMA and LAMA. In cases of non-inhaled drugs, theophylline and mucolytic agents were widely used. The medication usage of participants was represented in Table 2. A significantly high number of patients had at least one error in inhaler techniques $(91.3 \%$ in IG vs. $92.5 \%$ in $\mathrm{CG}$ ).

\section{Outcomes after the 3-month follow-up}

At baseline, the patients in both the IG and the NIG were found to have similar scores in QoL parameters including total CCQ scores and its domains - Symptoms, Functional state and Mental state $(\mathrm{p}>0.05)$ (Table 1). 
Table 3. Outcomes after the 3 month follow-up

* Mann-Whitney test

\begin{tabular}{lccc}
\hline \multirow{2}{*}{ Outcome after 3 months } & \multicolumn{2}{c}{ Group } & p value* \\
\cline { 2 - 4 } & IG $(\mathbf{n}=\mathbf{7 3})$ & NIG $(\mathbf{n}=\mathbf{6 8})$ & \\
\hline Total CCQ score & $0.81 \pm 0.54$ & $1.24 \pm 0.81$ & $\mathbf{0 . 0 0 1}$ \\
Symptom score & $1.09 \pm 0.82$ & $1.54 \pm 0.97$ & $\mathbf{0 . 0 0 4}$ \\
Functional state score & $0.85 \pm 0.62$ & $1.29 \pm 0.97$ & $\mathbf{0 . 0 1 1}$ \\
Mental state score & $0.17 \pm 0.38$ & $0.57 \pm 1.13$ & $\mathbf{0 . 0 2 6}$ \\
$\Delta$ Total CCQ score & $(-0.90) \pm 0.65$ & $(-0.26) \pm 0.74$ & $<\mathbf{0 . 0 0 1}$ \\
$\Delta$ Symptom score & $(-1.05) \pm 0.90$ & $(-0.29) \pm 0.98$ & $<\mathbf{0 . 0 0 1}$ \\
$\Delta$ Functional state score & $(-0.68) \pm 0.85$ & $(-0.18) \pm 0.86$ & $\mathbf{0 . 0 0 1}$ \\
$\Delta$ Mental state score & $(-1.03) \pm 1.42$ & $(-0.39) \pm 1.33$ & $\mathbf{0 . 0 0 2}$ \\
Inappropriate inhaler technique & $21(28.8 \%)$ & $66(97.1 \%)$ & $<\mathbf{0 . 0 0 1}$ \\
\hline
\end{tabular}

$\Delta$ score $=$ score after 3 months - baseline score

CCQ scores after the 3-month follow-up were shown in Table 3. The mean CCQ score in IG was significantly lower than that in NIG $(0.81 \pm$ 0.54 vs. $1.24 \pm 0.81, \mathrm{p}<0.001)$. It means the $\mathrm{QoL}$ improved significantly after pharmacist intervention. The scores of three domains, included Symptoms, Functional state and Mental state in the IG were also significantly lower than those in NIG $(\mathrm{p}<0.05)$. The best improvement was noted in the Mental state domain $(0.17 \pm 0.38$ in IG vs $0.57 \pm$ 1.13 in NIG, $\mathrm{p}=0.026$ ). In particular, the change $(\Delta)$ in QoL score in IG was significantly higher than that in the NIG, not only with respect to the total CCQ scores ((-0.90) \pm 0.65 in IG vs. (- 0.26) \pm 0.74 in NIG, $p<0.001)$ but also with respect to the three domains scores $(p<0.05)$. In addition, the result of multiple regression analysis showed that the pharmacist intervention really improved the QoL in patients with COPD $(\beta=-0.687, \mathrm{p}<0.001)$ (Table 4). At the end of the trial, the percentage of patients with error in inhaler techniques was significantly lower in the IG compared to the NIG $(28.8 \%$ in IG vs. $97.1 \%$ in NIG) (Table 4).

In order to investigate whether or not the loss-to-follow-up proportion (> 20\%) affected our findings, we performed three analyses. In the first one, referred as ITT analysis, results of multivariate regression analysis in all patients at randomization $(\mathrm{n}=$ 185) showed that intervention program was associated with a positive change in $\mathrm{QoL}(\beta=-$ $0.540, \mathrm{p}<0.001)($ Supplemental Table 1). In the second and third analysis, we assessed if there were any differences in the baseline characteristics between remaining patients and loss-to-follow-up patients after three months in the two groups. The result showed that, no statistically differences in baseline demographic features or CCQ scores between remaining patients and loss-to-follow-up patients in IG and NIG after three months were detected (Supplemental Table 2 and 3, respectively).

\section{DISCUSSION}

There was no statistically significant difference between the two study groups with respect to demographic measures and disease characteristics, medication characteristics and baseline QoL scores ( $\mathrm{p}>0.05$ ).

After the 3 month follow-up, the IG's mean CCQ score had clinically significant improvement (more than 0.4 points change in $\mathrm{CCQ}^{12} ; \mathrm{p}<0.05$ ) when compared with the NIG's. The QoL improvement in the IG had been shown in all three domains (Symptoms, Functional state and Mental state) of the CCQ scores ( $\mathrm{p}<0.05)$. The results of multivariate linear regression also reaffirmed the positive relationship between a pharmacist's education and intervention and an improvement in a patient's QoL ( $\mathrm{p}<0.001)$. As a result, this study has demonstrated the effectiveness of a pharmacist's consultation in improving QoL of COPD patients.

Table 4. Factors associated with the change in QoL scores after the 3-month follow-up with PP analysis

\begin{tabular}{lccc}
\hline \multicolumn{1}{c}{ Factor } & Changes in QoL scores $(\Delta)$ & $\boldsymbol{\beta}$ & p value* \\
\hline Intervention & & -0.691 & $<\mathbf{0 . 0 0 1}$ \\
Combination route & $\Delta$ total CCQ score & -0.375 & $\mathbf{0 . 0 1 0}$ \\
Current/Former smoker & & 0.836 & $\mathbf{0 . 0 1 3}$ \\
\hline
\end{tabular}

The factors, including age, body mass index, pack - year, education level, living area, GOLD classification, COPD duration, number of comorbidities, error in inhaler technique, that did not associate with the change in QoL were not mentioned in the table 4. *Multivariate linear regression 
In some previous studies, Khdour et al. ${ }^{13}$, Wei et al. ${ }^{14}$, Xin et al. ${ }^{15}$, Suhaj et al. ${ }^{16}$ had also reached a similar conclusion about the value of clinical pharmacist-led patient education. All these authors used St George's Respiratory Questionnaire (SGRQ) to access COPD patients' QoL. The SGRQ is an airways disease-specific questionnaire that examines three domains: symptoms ( 8 items), activity (16 items), and impacts (26 items). Ställberg ${ }^{17}$ showed that CCQ and SGRQ overall scores correlated strongly $(\mathrm{r}=$ 0.84). The correlation between Symptoms domains of SGRQ and CCQ was moderately $(r=$ 0.70). There was also a good correlation between the Impacts and Mental State domains. They also supported that the Functional State domain of CCQ corresponds to the Activity domain of SGRQ. In our study, we used CCQ, because it is shorter and easier to complete than SGRQ, allows data to be quickly collected and processed, and is thus suitable for use in practice.

Khdour et al. ${ }^{13}$ investigated the impact of a clinical pharmacy-led disease and medicine management programme on QoL of patients with COPD. Intervention patients received education on disease state, medications and inhaler techniques from a clinical pharmacist, while in the control group, patients received usual hospital outpatient care from doctor and nursing staff. Patients were followed up at 6 and 12 months during a scheduled visit. QoL of patients in IG was significantly improved at the 12-month follow-up point.

Wei et al. ${ }^{14}$ investigated whether pharmaceutical care could improve healthrelated quality of life in patients with COPD. The clinical pharmacist was mainly responsible for individualized education and a series of telephone counselling for 6 months. At the end of the study, scores on symptoms and impacts domains in the pharmaceutical care group were significantly improved compared with those in the control group $(40.68 \pm 18.59$ vs. $47.25 \pm$ $20.96, \mathrm{p}=0.032 ; 32.19 \pm 19.22$ vs. $41.36 \pm 25.66$, $\mathrm{p}=0.018$, respectively).

Xin et al. ${ }^{15}$ study was conducted in 2015 to access the impact of the pharmacist-managed clinic (PMC) on QoL in COPD patients. The $\mathrm{PMC}$ consisted of individualized education and a comprehensive pharmaceutical care program for patients provided by a clinical pharmacist. After 12 months, the total SGRQ scores improved significantly after the PMC intervention (42.7 \pm 3.2 vs. $52.4 \pm 5.2, p<0.05$ ), and the scores of three domains of symptoms, activities, and impacts in the PMC group were significantly improved. The best improvement was noted in the impacts domain $(30.8 \pm 2.4$ vs. $43.2 \pm 5.4$, p $<0.05$ )

Suhaj et al. ${ }^{16}$ study evaluated the effectiveness of clinical pharmacist intervention by laying emphasis on the importance of medication compliance, need for smoking cessation, simple exercise, proper use of inhaler devices and need for timely follow-up by pulmonary medicine department on QoL in COPD patients. The QoL score in the intervention group was significantly lower than that in the control group (60.40 vs. 68.50, respectively) $(\mathrm{p}<0.001)$. This denoted a higher QoL in the intervention group.

The similarity between results of our study and other previous studies was derived from the same research design - randomized controlled trials with pharmacist's intervention, the same method intervention based on patient face-to-face education as well as the same education materials about the pathophysiology of COPD, medicine usage, inhaler technique, the importance of medication adherence, ADE recognition and prevention, and lifestyle adjustments (smoking cessation, healthy diet, exercises). Furthermore, the regularity of monitoring and reminding patients about medication usage and treatment adherence is the key to achieving effectiveness, despite a short follow-up time.

Although many previous studies supported the positive impact of pharmacists on improving the QoL of COPD patients, studies of Jarab et al. ${ }^{18}$ and Tommelein et al. ${ }^{6}$ yielded different results. Jarab et al.'s study showed some improvement in total SGRQ score and its subscales at the 6-month assessment in the intervention group; however, the improvement in QoL failed to reach statistical significance ( $\mathrm{p}>$ $0.05)^{17}$. Meanwhile, Tommelein et al. used the EuroQol five-dimension questionnaire (EQ-5D) to accessed patient's QoL and did not find a significant difference in health status between intervention group $(0.72 \pm 0.24)$ and control group $(0.73 \pm 0.25)$ after 3 months $(p=0.19)^{6}$. The disagreement between these conclusions and ours may stem from dissimilarities in demographic characteristics (gender, duration of COPD, age) and frequency of patient access. In particular, while in our study, $97.8 \%$ were men, the rate of men gender was lower in Tommelein et al.'s and Jarab et al.'s studies $(66.1 \%$ and $40.6 \%$, respectively). Female patients are more 
concerned about health than men, so they have complied with medications and have higher QoL from the beginning, so the intervention does not affect them much. Besides, patients in both studies had a longer duration of COPD than ours. The longer the duration of the disease, the more familiar the patient is with controlling the disease, so the effect of the intervention will not be evident. In addition, Tommelein et al's study selected patients aged 50 and older, the average age of these patients was higher than ours. The older the patient, the lower the ability to remember, the lower the effectiveness of the intervention through education. Finally, the frequency of monitoring in Tommelein et al.'s and Jarab et al.'s studies was less regular than ours. The high frequency of repeated consultation can help to increase COPD control, belief in pharmacotherapy, and optimize inhaler usage skills, therefore increase patients' QoL. In Tommelein et al. study, patients in the intervention group received a protocol-defined two-session intervention; one session at the start of the study and one session at the 1 month follow-up visit, while in Jarab et al. study, patients were only counseled at the beginning of the study and reevaluated at the 6 month follow-up.

Our study showed that pharmacist-led counselling significantly improved QoL of COPD patients after 3 months. To the best of our knowledge, this is the first randomized controlled study in Vietnam that demonstrates the important role of patient education by clinical pharmacists on QoL of patients with COPD. The findings are envisaged to assist in the development of pharmacist advice models for prevention and management of chronic respiratory diseases in Vietnam.

In our study, in addition to pharmacist interventions, the results of multivariate regression analysis showed that a combination route and smoking status also affected patients' QoL scores in the third month. All patients in our study were prescribed inhalers, the addition of oral medication (mainly theophylline and mucolytic agents) helped improve the patient's symptoms and health condition, thereby improving patients' QoL. Former/current smoking factor reduced the QoL of COPD patients. In patients diagnosed with COPD, cigarette smoke worsened the progression of the disease with persistent respiratory inflammation, thereby leading to an increase in respiratory symptoms and lung function abnormalities. Cigarette smoke also increased secretion of mucus along with reduced lung defense mechanisms, paving the way for infection and acute exacerbations of COPD ${ }^{19}$.

\section{CONCLUSIONS}

Our study demonstrated that the clinical pharmacist educational intervention, including providing knowledge about COPD, face-to-face training in inhaler technique, counselling on medicine usage and ADE prevention, as well as regular reminders about medication adherence, improved patients' QoL. Therefore, clinical pharmacist can be good support for patients in the COPD management.

\section{ACKNOWLEDGMENTS}

The authors thank all the staff members of the Department of Screening Respiratory Function, University Medical Center, Ho Chi Minh City, for permission and helping the research group throughout the study process.

\section{Conflict of interest}

We have no conflict of interest to declare.

\section{Funding}

This study was financially supported by the Faculty of Pharmacy, University of Medicine and Pharmacy at Ho Chi Minh City, Vietnam.

\section{Ethical approval}

The protocol was approved by the Institutional Review Board of University of Medicine and Pharmacy at Ho Chi Minh City, Vietnam (Project Number: 605/ĐHYD-HĐ - 29/12/2017).

\section{Article info:}

Received March 25, 2019

Received in revised form October 27, 2019

Accepted November 2, 2019

\section{REFERENCES}

1. WHO. Global Surveillance, Prevention and Control of Chronic Respiratory Diseases: A Comprehensive Approach [document on the Internet]. Geneva: WHO; 2007 [accessed 2019]. Available from: http://www.who. int/gard/publications/

2. Lopez AD, Shibuya K, Rao C, Mathers CD, Hansell AL, Held LS, et al. Chronic obstructive pulmonary disease: current burden and future projections. Eur Respir J. 2006;27:297-412.

3. Regional COPD Working Group. COPD prevalence in 12 Asia-Pacific countries and regions: projections based on the COPD prevalence estimation model. Respirology. 2003;8(2):192-8.

4. GOLD. Global strategy for the Diagnosis, Management and Prevention of COPD [document on the Internet]. GOLD Committees; 2015 [updated January 2015; cited 
2019]. Available from: www.goldcopd.org.

5. George J, Kong DC, Thoman R, Stewart K. Factors associated with medication nonadherence in patients with COPD. Chest. 2005;128:3198-204.

6. Tommelein E, Mehuys E, Van Hees T, Adriaens E, Van Bortel L, Christiaens $\mathrm{T}$, et al. Effectiveness of pharmaceutical care for patients with chronic obstructive pulmonary disease (PHARMACOP): a randomized controlled trial. $\mathrm{Br} \mathrm{J}$ Clin Pharmacol. 2014;77(5):756-66.

7. Vo TH, Bedouch P, Nguyen TH, Nguyen TL, Hoang TK, Calop J, et al. Pharmacy Education in Vietnam. Am J Pharm Educ. 2013;77(6):114.

8. Le KB. Comparison value of $\mathrm{mMRC}$ and CCQ for symptom assessment in chronic obstructive pulmonary disease. HCMC J Med. 2015;19(1):541-9. (in Vietnamese)

9. GOLD. Global strategy for the Diagnosis, Management and Prevention of COPD [document on the Internet]. GOLD Committees; 2017 [updated 2017; cited 2019]. Available from: www.goldcopd.org.

10. Ministry of Health. Guidelines for diagnosis and treatment of respiratory diseases. Ha Noi: Vietnamese Medical Publisher; 2015. (in Vietnamese)

11. Le KB. Validity of CCQ (Clinical COPD questionnaire) on chronic obstructive pulmonary disease evaluation. HCMC J Med. 2012;16(1):58-63. (in Vietnamese)

12. Kocks JW, Tuinenga MG, Uil SM, van den Berg JW, Ståhl E, van der Molen T. Health status measurement in COPD: the minimal clinically important difference of the clinical COPD questionnaire. Respir Res. 2006;7:62.
13. Khdour MR, Kidney JC, Smyth BM, McElnay JC. Clinical pharmacy-led disease and medicine management programme for patients with COPD. Br J Clin Pharmacol. 2009;68(4):588-98.

14. Wei L, Yang X, Li J, Liu L, Luo H, Zheng Z, et al. Effect of pharmaceutical care on medication adherence and hospital admission in patients with chronic obstructive pulmonary disease (COPD): A randomized controlled study. J Thorac Dis. 2014;6(6):656-62.

15. Xin C, Xia Z, Jiang C, Lin M, Li G. The impact of pharmacist-managed clinic on medication adherence and health-related quality of life in patients with COPD: a randomized controlled study. Patient Prefer Adherence. 2016;10:1197-1203.

16. Suhaj A, Manu MK, Unnikrishnan MK, Vijayanarayana K, Mallikarjuna Rao C. Effectiveness of clinical pharmacist intervention on health-related quality of life in chronic obstructive pulmonary disorder patients - a randomized controlled study. J Clin Pharm Ther. 2016;41(1):78-83.

17. Ställberg B, Nokela M, Ehrs PO, Hjemdal P, Jonsson EW. Validation of the clinical COPD Questionnaire (CCQ) in primary care. Health Qual Life Outcomes. 2009;7:26.

18. Jarab AS, Alqudah SG, Khdour M, Shamssain M, Mukattash TL. Impact of pharmaceutical care on health outcomes in patients with COPD. Int J Clin Pharm. 2012;34(1):53-62.

19. Bartal M. COPD and tobacco smoke. Monaldi Arch Chest Dis. 2005;63(4):213-25. 
Supplemental Table 1: Factors associated with the change in QoL scores after the 3-month follow-up with ITT analysis $(\mathrm{n}=185)$

\begin{tabular}{lccc}
\hline \multicolumn{1}{c}{ Factor } & Changes in QoL scores $(\Delta)$ & $\boldsymbol{\beta}$ & p value* $^{*}$ \\
\hline Intervention & & -0.540 & $<\mathbf{0 . 0 0 1}$ \\
Combination route & $\Delta$ total CCQ score & -0.257 & $\mathbf{0 . 0 2 9}$ \\
Current/Former smoker & & 0.586 & $\mathbf{0 . 0 3 7}$ \\
\hline
\end{tabular}

The factors, including age, body mass index, pack - year, education level, living area, GOLD classification, COPD duration, number of comorbidities, error in inhaler technique, that did not associate with the change in QoL were not mentioned in the Supplemental Table 1 .

*Multivariate linear regression

Supplemental Table 2: Baseline characteristics of patients lost to follow-up and remaining after 3 months in the IG ( $n=92)$

\begin{tabular}{|c|c|c|c|c|c|}
\hline & & & $\mathbf{G r}$ & & \\
\hline & cteristics & $\begin{array}{c}\text { Overall } \\
(n=92)\end{array}$ & $\begin{array}{l}\text { Loss-to-follow- } \\
\text { up IG }(n=19)\end{array}$ & $\begin{array}{c}3^{\text {rd }} \text { month } \\
\text { remaining IG } \\
(n=73)\end{array}$ & p value \\
\hline Gender (Male) & & $91(98.9 \%)$ & $18(94.7 \%)$ & $73(100 \%)$ & 0.050 \\
\hline Mean Age & & $63.80 \pm 9.96$ & $64.11 \pm 9.44$ & $63.73 \pm 10.15$ & 0.883 \\
\hline $40-60$ & & $31(33.7 \%)$ & $6(31.6 \%)$ & $25(34.2 \%)$ & \\
\hline$\geq 60$ & & $61(66.3 \%)$ & $13(68.4 \%)$ & $48(65.8 \%)$ & 0.827 \\
\hline BMI $\left(\mathrm{kg} / \mathrm{m}^{2}\right)$ & & $21.49 \pm 3.24$ & $20.64 \pm 2.65$ & $21.71 \pm 3.36$ & 0.201 \\
\hline Education level & Illiterate & $1(1.1 \%)$ & $1(5.3 \%)$ & $0(0 \%)$ & \\
\hline & Primary & $25(27.2 \%)$ & $7(36.8 \%)$ & $18(24.7 \%)$ & \\
\hline & Secondary & $31(33.7 \%)$ & $5(26.3 \%)$ & $26(35.6 \%)$ & \\
\hline & High school & $26(28.3 \%)$ & $4(21.1 \%)$ & $22(30.1 \%)$ & 0.239 \\
\hline & University/ college & $9(9.8 \%)$ & $2(10.5 \%)$ & $7(9.6 \%)$ & \\
\hline & Postgrad & $0(0 \%)$ & $0(0 \%)$ & $0(0 \%)$ & \\
\hline Living area & Rural & $58(63.0 \%)$ & $13(68.4 \%)$ & $45(61.6 \%)$ & \\
\hline & Urban & $34(37.0 \%)$ & $6(31.6 \%)$ & $28(38.4 \%)$ & 0.586 \\
\hline Smoking status & Non - smoker & $3(3.3 \%)$ & $1(5.3 \%)$ & $2(2.7 \%)$ & \\
\hline & Former smoker & $63(68.5 \%)$ & $11(57.9 \%)$ & $52(71.2 \%)$ & 0.519 \\
\hline & Current smoker & $26(28.3 \%)$ & $7(36.8 \%)$ & $19(26.0 \%)$ & \\
\hline Pack - year & & $34.91 \pm 18.59$ & $32.37 \pm 16.28$ & $35.58 \pm 19.18$ & 0.506 \\
\hline GOLD & A & $5(5.4 \%)$ & $2(10.5 \%)$ & $3(4.1 \%)$ & \\
\hline classification & $\mathrm{B}$ & $27(29.3 \%)$ & $6(31.6 \%)$ & $21(28.8 \%)$ & 0656 \\
\hline & $\mathrm{C}$ & $18(19.6 \%)$ & $4(21.1 \%)$ & $14(19.2 \%)$ & 0.656 \\
\hline & $\mathrm{D}$ & $42(45.7 \%)$ & $7(36.8 \%)$ & $35(47.9 \%)$ & \\
\hline COPD duration & & $3.88 \pm 3.80$ & $3.66 \pm 3.10$ & $3.93 \pm 3.97$ & 0.934 \\
\hline Comorbidities & Yes & $78(84.8 \%)$ & $14(73.7 \%)$ & $64(87.7 \%)$ & 0.131 \\
\hline & Hypertension & $43(46.7 \%)$ & $6(31.6 \%)$ & $37(50.7 \%)$ & 0.137 \\
\hline & Gastritis & $15(16.3 \%)$ & $3(15.8 \%)$ & $12(16.4 \%)$ & 0.946 \\
\hline & Ischemic heart disease & $10(10.9 \%)$ & $0(0 \%)$ & $10(13.7 \%)$ & 0.087 \\
\hline Inappropriate inl & r technique & $84(91.3 \%)$ & $17(89.5 \%)$ & $67(91.8 \%)$ & 0.751 \\
\hline Total CCQ score & & $1.73 \pm 0.95$ & $1.79 \pm 1.09$ & $1.71 \pm 0.92$ & 0.843 \\
\hline Symptom score & & $2.16 \pm 1.11$ & $2.21 \pm 1.16$ & $2.14 \pm 1.10$ & 0.817 \\
\hline Functional state & & $1.54 \pm 1.10$ & $1.61 \pm 1.20$ & $1.52 \pm 1.08$ & 0.873 \\
\hline Mental state sco & & $1.23 \pm 1.56$ & $1.34 \pm 1.85$ & $1.21 \pm 1.49$ & 0.918 \\
\hline
\end{tabular}

Mean age, BMI, pack - year, COPD duration, total CCQ score, symptom score, functional state score, mental state score were compared using t-test or Mann-Whitney test. Rates of gender, age group, education level, smoking status, GOLD classification, comorbidities were $\mathrm{Chi}$ - square test. 
Supplemental Table 3: Baseline characteristics of patients lost to follow-up and remaining after 3 months in the NIG (n=93)

\begin{tabular}{|c|c|c|c|c|c|}
\hline & & & & & \\
\hline Ch & teristics & $\begin{array}{c}\text { Overall } \\
(n=93)\end{array}$ & $\begin{array}{l}\text { Loss-to-follow- } \\
\text { up NIG }(n=25)\end{array}$ & $\begin{array}{c}3^{\text {rd }} \text { month } \\
\text { remaining NIG } \\
(n=68)\end{array}$ & p value \\
\hline Gender (Male) & & $90(96.8 \%)$ & $25(100 \%)$ & $65(95.6 \%)$ & 0.286 \\
\hline Mean Age & & $66.08 \pm 8.67$ & $64.60 \pm 9.32$ & $66.62 \pm 8.43$ & 0.323 \\
\hline $40-60$ & & $20(21.5 \%)$ & $6(24.0 \%)$ & $14(20.6 \%)$ & \\
\hline$\geq 60$ & & $73(78.5 \%)$ & $19(76.0 \%)$ & $54(79.4 \%)$ & 0.723 \\
\hline BMI $\left(\mathrm{kg} / \mathrm{m}^{2}\right)$ & & $21.83 \pm 3.55$ & $21.89 \pm 3.10$ & $21.81 \pm 3.73$ & 0.920 \\
\hline & Illiterate & $1(1.1 \%)$ & $0(0 \%)$ & $1(1.5 \%)$ & \\
\hline & Primary & $31(33.3 \%)$ & $6(24.0 \%)$ & $25(36.8 \%)$ & \\
\hline & Secondary & $22(23.7 \%)$ & $9(36.0 \%)$ & $13(19.1 \%)$ & \\
\hline Education level & High school & $27(29.0 \%)$ & $8(32.0 \%)$ & $19(27.9 \%)$ & 0.499 \\
\hline & University/ college & $11(11.8 \%)$ & $2(8.0 \%)$ & $9(13.2 \%)$ & \\
\hline & Postgrad & $1(1.1 \%)$ & $0(0 \%)$ & $1(1.5 \%)$ & \\
\hline & Rural & $54(58.1 \%)$ & $13(52.0 \%)$ & $41(60.3 \%)$ & \\
\hline Living area & Urban & $39(41.9 \%)$ & $12(48.0 \%)$ & $27(39.7 \%)$ & 0.472 \\
\hline & Non - smoker & $4(4.3 \%)$ & $1(4.0 \%)$ & $3(4.4 \%)$ & \\
\hline Smoking status & Former smoker & $64(68.8 \%)$ & $17(68.0 \%)$ & $47(69.1 \%)$ & 0.987 \\
\hline & Current smoker & $25(26.9 \%)$ & $7(28.0 \%)$ & $18(26.5 \%)$ & \\
\hline Pack - year & & $36.73 \pm 18.90$ & $37.88 \pm 16.48$ & $36.31 \pm 19.82$ & 0.497 \\
\hline & A & $5(5.4 \%)$ & $0(0 \%)$ & $5(7.4 \%)$ & \\
\hline GOLD & B & $29(31.2 \%)$ & $9(36.0 \%)$ & $20(29.4 \%)$ & A 375 \\
\hline classification & $\mathrm{C}$ & $10(10.8 \%)$ & $4(16.0 \%)$ & $6(8.8 \%)$ & $0.3 / 5$ \\
\hline & $\mathrm{D}$ & $49(52.7 \%)$ & $12(48.0 \%)$ & $37(54.4 \%)$ & \\
\hline COPD duration & & $4.63 \pm 4.52$ & $4.40 \pm 4.60$ & $4.72 \pm 4.52$ & 0.651 \\
\hline & Yes & $69(74.2 \%)$ & $18(72.0 \%)$ & $51(75.0 \%)$ & 0.769 \\
\hline & Hypertension & $42(45.2 \%)$ & $12(48.0 \%)$ & $30(44.1 \%)$ & 0.739 \\
\hline Comorbidities & Gastritis & $14(15.1 \%)$ & $2(8.0 \%)$ & $12(17.6 \%)$ & 0.249 \\
\hline & $\begin{array}{l}\text { Ischemic heart } \\
\text { disease }\end{array}$ & $12(12.9 \%)$ & $2(8.0 \%)$ & $10(14.7 \%)$ & 0.392 \\
\hline Inappropriate in & r technique & $86(92.5 \%)$ & $23(92.0 \%)$ & $63(92.6 \%)$ & 0.916 \\
\hline Total CCQ scor & & $1.57 \pm 1.05$ & $1.73 \pm 1.01$ & $1.51 \pm 1.07$ & 0.241 \\
\hline Symptom score & & $1.90 \pm 1.08$ & $2.11 \pm 1.02$ & $1.82 \pm 1.10$ & 0.251 \\
\hline Functional state & & $1.53 \pm 1.32$ & $1.71 \pm 1.27$ & $1.46 \pm 1.34$ & 0.302 \\
\hline Mental state sco & & $0.98 \pm 1.60$ & $1.02 \pm 1.79$ & $0.96 \pm 1.54$ & 0.996 \\
\hline
\end{tabular}

Mean age, BMI, pack - year, COPD duration, total CCQ score, symptom score, functional state score, mental state score were compared using t-test or Mann-Whitney test. Rates of gender, age group, education level, smoking status, GOLD classification, comorbidities were Chi - square test. 